\title{
Mismatch repair-deficient prostate cancer with parenchymal brain metastases treated with immune checkpoint blockade
}

\author{
Laura A. Sena, ${ }^{1,2,5}$ Daniela C. Salles, ${ }^{1,5}$ Elizabeth L. Engle, ${ }^{2,3}$ Qingfeng Zhu, ${ }^{1}$ \\ Hanna Tukachinsky, ${ }^{4}$ Tamara L. Lotan, ${ }^{1}$ and Emmanuel S. Antonarakis ${ }^{1,2}$ \\ ${ }^{1}$ The Sidney Kimmel Comprehensive Cancer Center, ${ }^{2}$ The Bloomberg Kimmel Institute for Cancer \\ Immunotherapy, ${ }^{3}$ Department of Dermatology, Johns Hopkins University School of Medicine, Baltimore, \\ Maryland 21205, USA; ${ }^{4}$ Foundation Medicine Inc., Cambridge, Massachusetts 02141, USA
}

Abstract Parenchymal brain metastases from prostate cancer are unusual and are associated with poor prognosis. Given the rarity of this entity, little is known about its molecular and histologic characteristics. Here we describe a patient with metastatic castration-resistant, mismatch repair-deficient (dMMR) prostate cancer with parenchymal brain metastases. Analysis of a brain metastasis revealed MLH1 loss consistent with dMMR, yet few tumor-infiltrating lymphocytes (TILs). He was treated with immune checkpoint blockade (ICB) and exhibited an extra-central nervous system (CNS) systemic response but CNS progression. Subsequent assessment of a brain metastasis following ICB treatment surprisingly showed increased TIL density and depletion of macrophages, suggestive of an enhanced antitumor immune response. Post-treatment tumoral DNA sequencing did not reveal acquired mutations that might confer resistance to ICB. This is the first description of ICB therapy for a patient with prostate cancer with parenchymal brain metastases, with pre- and post-treatment immunogenomic analyses.

[Supplemental material is available for this article.]

Corresponding author: eantona1@jhmi.edu

(C) 2021 Sena et al. This article is distributed under the terms of the Creative Commons Attribution-NonCommercial License, which permits reuse and redistribution, except for commercial purposes, provided that the original author and source are credited.

Ontology term: prostate cancer

Published by Cold Spring Harbor Laboratory Press

doi:10.1101/mcs.a006094

\section{INTRODUCTION}

Prostate cancer most frequently metastasizes to bone, lymph nodes, liver, and lung (Gandaglia et al. 2014). Metastases to the central nervous system (CNS) are rare. A retrospective study of patients with prostate cancer seen at MD Anderson Cancer Center from 1944 to 1998 estimated the incidence of brain metastases to be $0.6 \%$ (Tremont-Lukats et al. 2003). Even among men who die from prostate cancer, the rate of brain metastases has been reported to be in the range of $2 \%$ to $4 \%$ in autopsy studies (Catane et al. 1976; Saitoh et al. 1984). This is in contrast to other common malignancies such as lung, breast, and colon cancers, which are estimated to have incidences of brain metastases of $39 \%-56 \%, 15 \%-30 \%$, and 3\%-8\%, respectively (Nayak et al. 2012). In prostate cancer, brain metastases are almost always associated with heavily pretreated, widely metastatic, castration-resistant disease (Mota et al. 2019). In fact, isolated metastasis of prostate cancer to the brain parenchyma has only been reported in the literature four times (Lewis 1967; Smith et al. 1980; Gupta

\footnotetext{
${ }^{5}$ These authors contributed equally to this work.
} 
et al. 1994; Sutton et al. 1996). Why prostate cancer generally fails to produce brain metastases is an unanswered question; however, the association of brain metastases with advanced disease may suggest that the tumor or immune system must undergo adaptation to allow these cancer cells to enter, survive, and/or grow in the CNS. Once brain metastases develop from prostate cancer, the prognosis is poor, with survival being on the order of 2-6 mo (Hatzoglou et al. 2014; Mota et al. 2019).

Given the rarity of prostate cancer with brain metastases, little is known about its molecular characteristics and its interaction with the immune microenvironment. Initial studies suggested that PTEN loss and DNA homologous repair (HR) mutations may be common in this entity (Mota et al. 2019; Rodriguez et al. 2020); however, relatively few tumors have undergone DNA sequencing to date. Moreover, the immune cell composition of brain metastases from prostate cancer has not previously been described.

Here we present a patient with metastatic castration-resistant prostate cancer (mCRPC) with brain metastases, whose tumor was found to have DNA mismatch repair deficiency (dMMR) with few $\mathrm{CD}^{+}$tumor-infiltrating lymphocytes (TILs) but abundant macrophages. Given the efficacy of immune checkpoint blockade in cancers of varying primary histology with dMMR (Le et al. 2017), the patient was treated with the anti-PD1 antibody pembrolizumab. We describe the clinical and immunogenomic features of this patient.

\section{RESULTS}

\section{Case Description}

A 60-yr-old man was found to have a prostate-specific antigen (PSA) level of $15.3 \mathrm{ng} / \mathrm{mL}$ and was subsequently diagnosed with localized prostate adenocarcinoma with Gleason score $4+$ $5=9$. He underwent primary external-beam radiotherapy with concurrent androgen-deprivation therapy that was planned for 2 yr. However, 18 mo after radiation was completed, he was found to have a rising PSA level despite castrate levels of testosterone and was deemed to have castration-resistant prostate cancer (CRPC). Imaging studies revealed bone metastases and retroperitoneal lymphadenopathy. He was treated with sipuleucel-T immunotherapy, followed by abiraterone and prednisone, but developed disease progression after $8 \mathrm{mo}$. At that time, he developed slurred speech and difficulty recalling names and performing complex business planning. Magnetic resonance imaging (MRI) of the brain revealed more than 15 parenchymal brain lesions (Fig. 1A,B).

Given the rarity of parenchymal brain metastases from prostate cancer, the patient underwent diagnostic and therapeutic craniotomy with excision of the two largest brain tumors, with pathology confirming metastatic prostatic adenocarcinoma with extensive necrosis (Fig. 2A). Multispectral immunofluorescence and immunohistochemical studies revealed a paucity of $\mathrm{CD} 8^{+}$TILs (Fig. 2C,E) and abundant $\mathrm{CD} 163^{+}$macrophages in the initial tissue sample (Fig. 2G). The patient then received postoperative stereotactic radiation therapy to 14 separate brain metastases and was concurrently started on enzalutamide.

Next-generation DNA sequencing of his resected brain tumor (FoundationOne CDx) revealed multiple genomic alterations including MLH1 homozygous deletion with microsatellite instability (MSI-high) and a tumor mutational burden of 25 mutations/Mb, indicating dMMR (Table 1; Supplemental Table S1). The patient's tumor frameshift mutation burden was 11.25 mutations/Mb, and frameshift mutation proportion was $22 \%$. Immunohistochemistry for the four mismatch repair proteins showed loss of MLH1 and its binding partner PMS2, with intact expression of MSH2 and MSH6 (Supplemental Fig. S1). He was noted to have a family history of prostate cancer in his father and breast cancer in his sister; however, germline genetic testing using an 84-gene panel (Invitae) was negative for pathogenic germline mutations. 

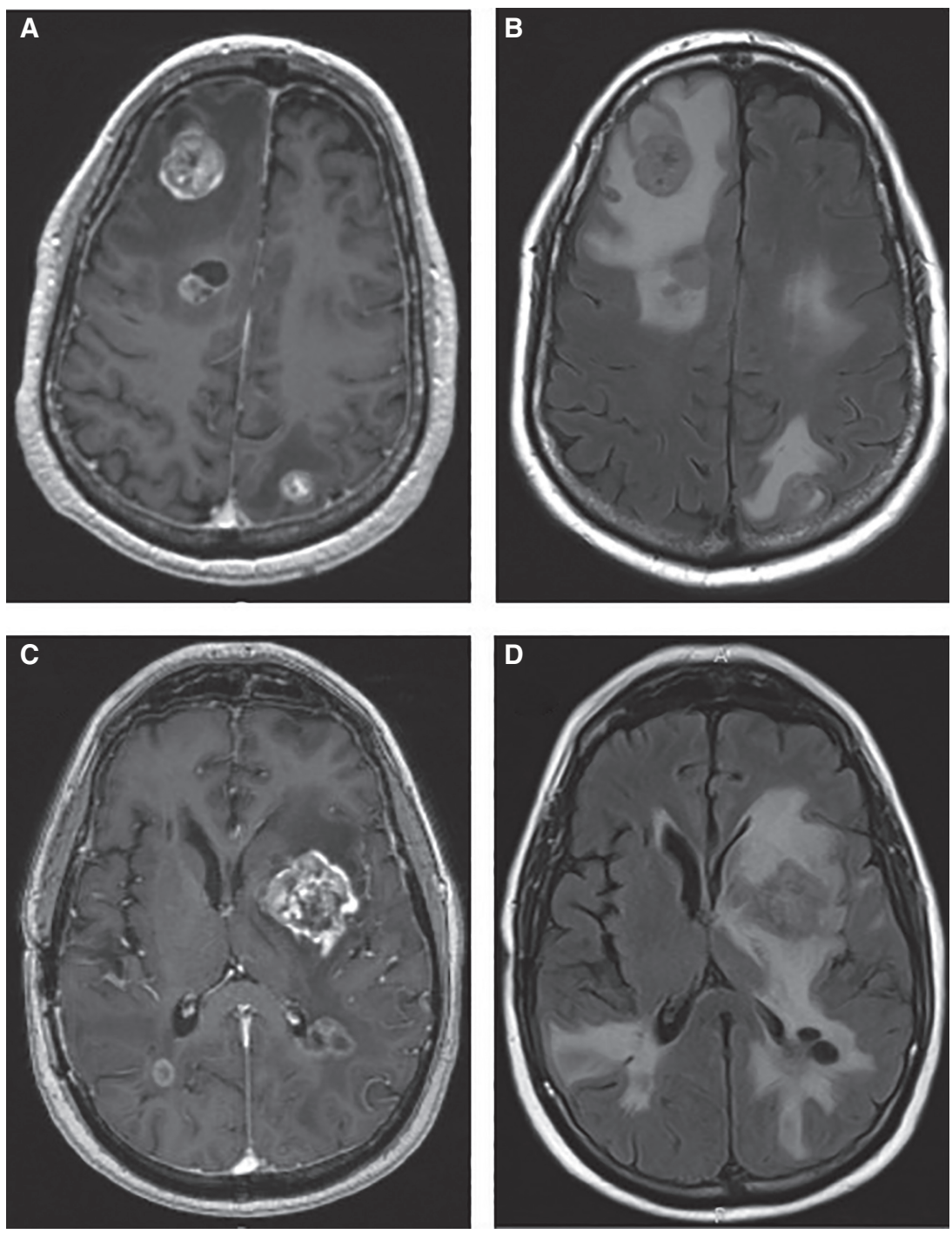

Figure 1. Parenchymal brain metastases from prostate cancer. (A) Brain magnetic resonance imaging (MRI) axial view of T1 contrast-enhanced image demonstrates several parenchymal brain lesions. (B) Corresponding axial view of T2-FLAIR (T2-weighted fluid attenuated inversion recovery) image demonstrates surrounding vasogenic edema. (C) Post-treatment with pembrolizumab, MRI axial view of T1 contrast-enhanced image suggests enlargement of parenchymal brain lesions. (D) Post-treatment with pembrolizumab, corresponding axial view of T2-FLAIR image demonstrates surrounding vasogenic edema.

The patient was then started on ICB therapy using pembrolizumab 200 mg intravenously every $3 \mathrm{wk}$. This resulted in a PSA decline of 79\%, as well as a partial radiographic response in his metastatic lymphadenopathy. The patient's functional status also improved, with increased appetite and healthy weight gain. However, after his third dose of pembrolizumab, he developed confusion, expressive aphasia, and impaired coordination of his right hand. MRI of the brain showed multiple new and enlarging metastatic parenchymal brain lesions, with worsening vasogenic edema and slight midline shift (Fig. 1C,D).

He was initiated on dexamethasone and underwent repeat craniotomy with excision of an enlarging tumor followed by brain-directed radiotherapy. This second tumor sample 

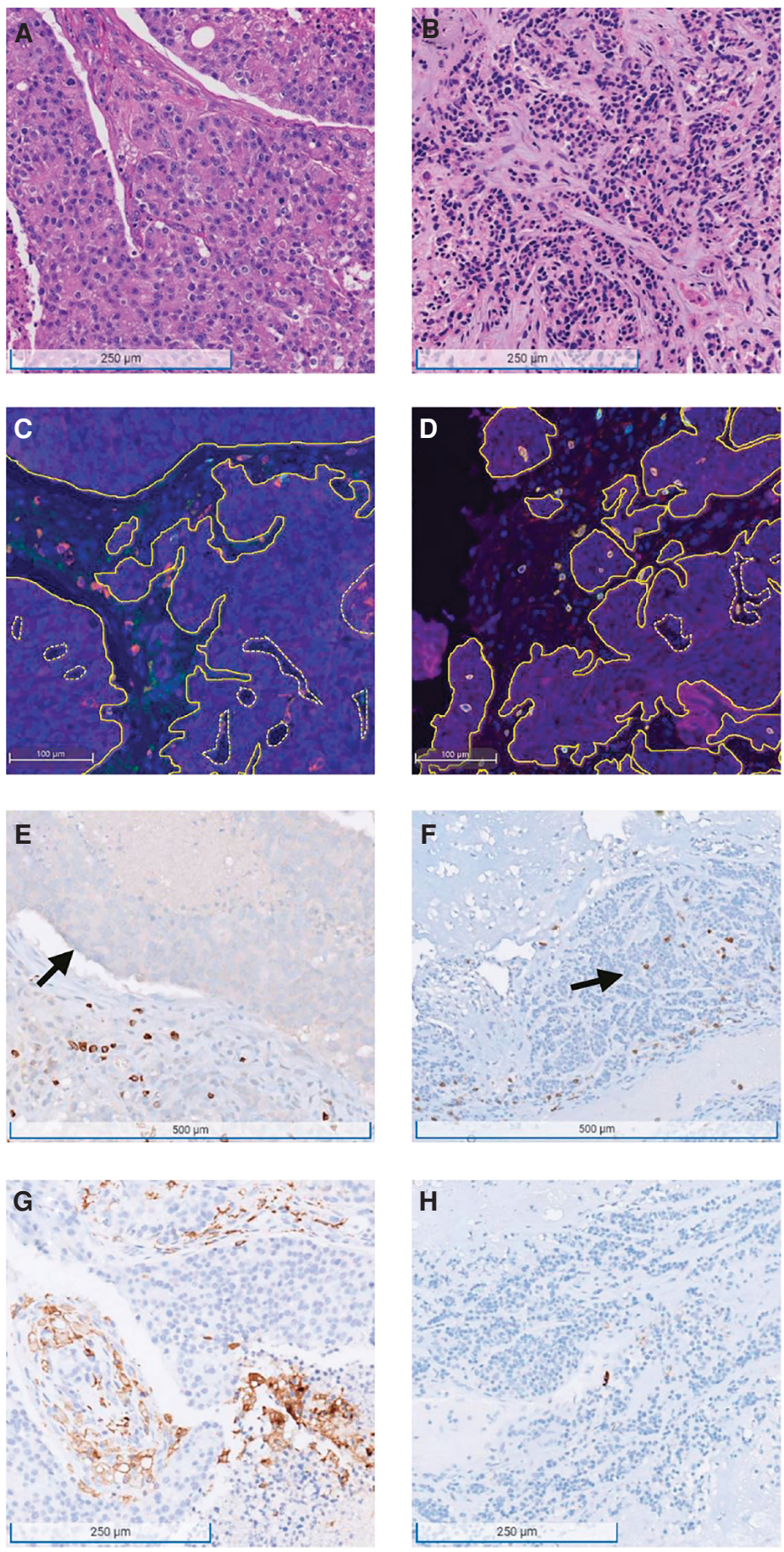

Figure 2. Pathologic response to immune checkpoint blockade (ICB). (A) Hematoxylin and eosin (H\&E) image of pretreatment sample demonstrates large, solid tumor nests. (B) H\&E image of post-treatment sample demonstrates smaller tumor cells arranged in smaller nests. (C) Multiplex immunofluorescence (mIF) image of pretreatment sample showing CD8 (yellow), CD68 (orange), PD1 (aqua), and DAPI (blue) staining. Epithelial regions are manually annotated for analysis (yellow lines) using HALO software with some areas excluded from analysis (dotted white lines). (D) mIF image of post-treatment sample showing CD8 (yellow), CD68 (orange), PD1 (aqua), and DAPI (blue) staining. (E) Immunohistochemistry for CD8 in pretreatment sample shows lymphocytes mainly in stromal regions and excluded from tumor areas (arrow). (F) Immunohistochemistry for CD8 in post-treatment sample shows lymphocytes admixed with tumor cells (arrow). (G) Immunohistochemistry for CD163 in pretreatment sample demonstrates abundant macrophages in tumor and stromal areas. $(H)$ Immunohistochemistry for CD163 in post-treatment sample shows only rare macrophages. 
Table 1. Next-generation DNA sequencing of brain tumor specimens (FoundationOne CDx, Cambridge, MA) collected before and after pembrolizumab therapy

\begin{tabular}{|c|c|c|c|}
\hline Gene/Biomarker & Location & $\begin{array}{l}\text { Pre-ICB brain metastasis biomarker status } \\
\text { or HGVS reference (DNA; Protein) }\end{array}$ & $\begin{array}{l}\text { Post-ICB brain metastasis biomarker status } \\
\text { or HGVS reference (DNA; Protein) }\end{array}$ \\
\hline Microsatellite status & NA & MSI-high & MSI-high \\
\hline $\begin{array}{l}\text { Tumor mutational } \\
\text { burden }\end{array}$ & NA & 25 mutations $/ \mathrm{Mb}$ & 29 mutations/Mb \\
\hline $\begin{array}{l}\text { Tumor FS } \\
\text { mutational } \\
\text { burden }\end{array}$ & NA & 10 mutations/Mb & 11 mutations/Mb \\
\hline $\begin{array}{l}\text { Tumor FS } \\
\text { proportion }\end{array}$ & NA & $22 \%$ & $24 \%$ \\
\hline MLH1 & $\begin{array}{l}\text { Chromosome 3, } \\
\text { NC_000003.12 }\end{array}$ & Homozygous loss & Homozygous loss \\
\hline$A P C$ & $\begin{array}{l}\text { Chromosome 5, } \\
\text { NC_000005.10 }\end{array}$ & c.4393_4394delAG; p.S1465fs*3 & c.4393_4394delAG; p.S1465fs*3 \\
\hline$A P C$ & $\begin{array}{l}\text { Chromosome 5, } \\
\text { NC_000005.10 }\end{array}$ & c. $5362 C>T ; p . R 1788 C$ & c. $5362 C>T ; R 1788 C$ \\
\hline AXIN1 & $\begin{array}{r}\text { Chromosome 16, } \\
\text { NC_000016.10 }\end{array}$ & c. 1602 C > A; p.H534Q & Not detected \\
\hline ARID1A & $\begin{array}{l}\text { Chromosome 1, } \\
\text { NC_000001.11 }\end{array}$ & c.3402_3403delTC; p.P1135fs*57 & c.3402_3403delTC; p.P1135fs*57 \\
\hline ASXL1 & $\begin{array}{r}\text { Chromosome 20, } \\
\text { NC_000020.11 }\end{array}$ & c.1934_1935insG; p.G646fs*12 & c.1934_1935insG; p.G646fs*12 \\
\hline BCORL1 & $\begin{array}{l}\text { Chromosome X, } \\
\text { NC_000023.11 }\end{array}$ & c.5042delC; p. P1681fs*20 & c.5042delC; p. P1681fs*20 \\
\hline CCND3 & $\begin{array}{l}\text { Chromosome 6, } \\
\text { NC_000006.12 }\end{array}$ & Not detected & c.869T >A; p. $1290 \mathrm{~K}$ \\
\hline CD79A & $\begin{array}{l}\text { Chromosome 19, } \\
\text { NC_000019.10 }\end{array}$ & Not detected & c.205G > A; p.V69l \\
\hline CDKN2A & $\begin{array}{l}\text { Chromosome 9, } \\
\text { NC_000009.12 }\end{array}$ & Homozygous loss & Homozygous loss \\
\hline CDKN2B & $\begin{array}{l}\text { Chromosome 9, } \\
\text { NC_000009.12 }\end{array}$ & Homozygous loss & Homozygous loss \\
\hline $\mathrm{ClC}$ & $\begin{array}{l}\text { Chromosome 19, } \\
\text { NC_000019.10 }\end{array}$ & c. 4790 delC; p.P1597fs*23 & c. 4790 delC; p.P1597fs*23 \\
\hline $\mathrm{ClC}$ & $\begin{array}{r}\text { Chromosome 19, } \\
\text { NC_000019.10 }\end{array}$ & c.3554C>T; p.A1185V & c.3554C > T; p.A1185V \\
\hline FAM46C & $\begin{array}{l}\text { Chromosome 1, } \\
\text { NC_000001.11 }\end{array}$ & c.694G > A; p.A232T & Not detected \\
\hline JAK1 & $\begin{array}{l}\text { Chromosome 1, } \\
\text { NC_000001.11 }\end{array}$ & c.1289_1290insC; p.L431fs*22 & c.1289_1290insC; p.L431fs*22 \\
\hline JAK1 & $\begin{array}{l}\text { Chromosome 1, } \\
\text { NC_000001.11 }\end{array}$ & c. $2842+2 T>G ;$ p.splice site $2842+2 T>G$ & $\begin{array}{l}\text { c. } 2842+2 T>G \text { splice site mutation; p.splice } \\
\text { site } 2842+2 T>G\end{array}$ \\
\hline KDM5C & $\begin{array}{l}\text { Chromosome } X_{1} \\
\text { NC_000023.11 }\end{array}$ & c.3447C > T; p.A1149T & Not detected \\
\hline MAP2K4 & $\begin{array}{l}\text { Chromosome 17, } \\
\text { NC_000017.11 }\end{array}$ & c. $633+2 T>A ;$ p.splice site $633+2 T>A$ & c. $633+2 T>A ;$ p.splice site $633+2 T>A$ \\
\hline MLL2 & $\begin{array}{r}\text { Chromosome } 12 \\
\text { NC_000012.12 }\end{array}$ & c. 15640 C > T, p.R5214C & Not detected \\
\hline
\end{tabular}

(Continued on next page.) 


\begin{tabular}{|c|c|c|c|}
\hline Gene/Biomarker & Location & $\begin{array}{l}\text { Pre-ICB brain metastasis biomarker status } \\
\text { or HGVS reference (DNA; Protein) }\end{array}$ & $\begin{array}{l}\text { Post-ICB brain metastasis biomarker status } \\
\text { or HGVS reference (DNA; Protein) }\end{array}$ \\
\hline MTAP & $\begin{array}{l}\text { Chromosome 9, } \\
\text { NC_000009.12 }\end{array}$ & Homozygous loss & Homozygous loss \\
\hline NF1 & $\begin{array}{l}\text { Chromosome 17, } \\
\text { NC_000017.11 }\end{array}$ & c.7595C > T; p.A2532V & c.7595C > T; p.A2532V \\
\hline NFKBIA & $\begin{array}{l}\text { Chromosome 14, } \\
\text { NC_000014.9 }\end{array}$ & Not detected & c.560T > C; p.L187P \\
\hline PIK3CB & $\begin{array}{l}\text { Chromosome 3, } \\
\text { NC_000003.12 }\end{array}$ & c.1810delC; p.R604fs*4 & c.1810delC; p.R604fs*4 \\
\hline PBRM1 & $\begin{array}{l}\text { Chromosome 3, } \\
\text { NC_000003.12 }\end{array}$ & c.2101A > T; p.K701* & c.2101A > T; p.K701* \\
\hline PBRM1 & $\begin{array}{l}\text { Chromosome 3, } \\
\text { NC_000003.12 }\end{array}$ & c.2727A > C; p.K909N & c.2727A > C; p.K909N \\
\hline PTEN & $\begin{array}{l}\text { Chromosome 10, } \\
\text { NC_000010.11 }\end{array}$ & $\begin{array}{l}\text { c.802-3_802-1TAG > AA; p. splice site 802- } \\
\text { 3_802-1TAG > AA }\end{array}$ & $\begin{array}{l}\text { c.802-3_802-1TAG > AA; p.splice site 802- } \\
\text { 3_802-1TAG > AA }\end{array}$ \\
\hline PTEN & $\begin{array}{l}\text { Chromosome 10, } \\
\text { NC_000010.11 }\end{array}$ & c. $209+2 T>C ;$ p.splice site $209+2 T>C$ & c. $209+2 T>C ;$ p.splice site $209+2 T>C$ \\
\hline PTEN & $\begin{array}{l}\text { Chromosome 10, } \\
\text { NC_000010.11 }\end{array}$ & c.802-1G > A; p.slice site $802-1 \mathrm{G}>\mathrm{A}$ & Not detected \\
\hline SPEN & $\begin{array}{l}\text { Chromosome 1, } \\
\text { NC_000001.11 }\end{array}$ & Not detected & c. 2419 C > T; p.R807C \\
\hline
\end{tabular}

Only selected alterations are shown (a full list of all reported alterations is included in the Supplemental Appendix). Alterations that changed between samples are shaded.

(ICB) Immune checkpoint blockade, (NA) not applicable, (FS) frameshift.

showed prostate adenocarcinoma with increased stromal content compared to the prior sample (Fig. 2B). Interestingly, despite clinical CNS progression, multiplex immunofluorescence and immunohistochemical studies revealed significantly increased numbers of $\mathrm{CD}^{+}$tumor-infiltrating $\mathrm{T}$ cells (Fig. 2D,F). The median density of $\mathrm{CD}^{+} \mathrm{T}$ cells located within the tumor epithelium increased from 5.6 cells $/ \mathrm{mm}^{2}$ pretreatment to $51.5 \mathrm{cell} / \mathrm{sm} \mathrm{m}^{2}$ posttreatment $(P<0.0001)$ (Fig. 3A). The density of $\mathrm{PD} 1^{+}$cells also increased post-treatment $(P=0.005)$ (Fig. 3B). Conversely, macrophages decreased from a median density of 176.5 cells $/ \mathrm{mm}^{2}$ to $56.2 \mathrm{cells} / \mathrm{mm}^{2}(P=0.011)$ (Figs. $2 \mathrm{H}, 3 \mathrm{C}$ ). Of note, assessment of the patient's prior stereotactic radiosurgery plans showed that the analyzed tumor was not previously encompassed within the radiation field.

We considered whether the tumor had acquired a genomic alteration that might alter the tumor immune contexture. Somatic DNA sequencing of the post-treatment brain tumor sample (FoundationOne CDx) revealed a new missense variant in NFKBIA (p.L187P) with high allele frequency (Table 1). NFKBIA encodes $\mid \kappa B \alpha$, which binds and inhibits nuclear localization and transcriptional activity of the NF- $\mathrm{kB}$ complex, and its inactivation leads to constitutive NF-kB activity (Taniguchi and Karin 2018). However, immunohistochemistry for the $N F-\kappa B$ subunit 65 did not show enhanced nuclear localization, indicating that this missense change was probably not inactivating (Supplemental Fig. S2). Therefore, the changes in tumor immune cell composition was attributed to pembrolizumab treatment.

Given the clear ongoing extra-CNS response and the suggestion of an immune CNS response, the patient was continued on pembrolizumab for a total of 6 mo until he developed eventual PSA progression and worsening metastatic lymphadenopathy. At that time, he was initiated on docetaxel chemotherapy and experienced a PSA response as well as an 
COLD SPRING HARBOR Molecular Case Studies
dMMR prostate cancer with brain metastases
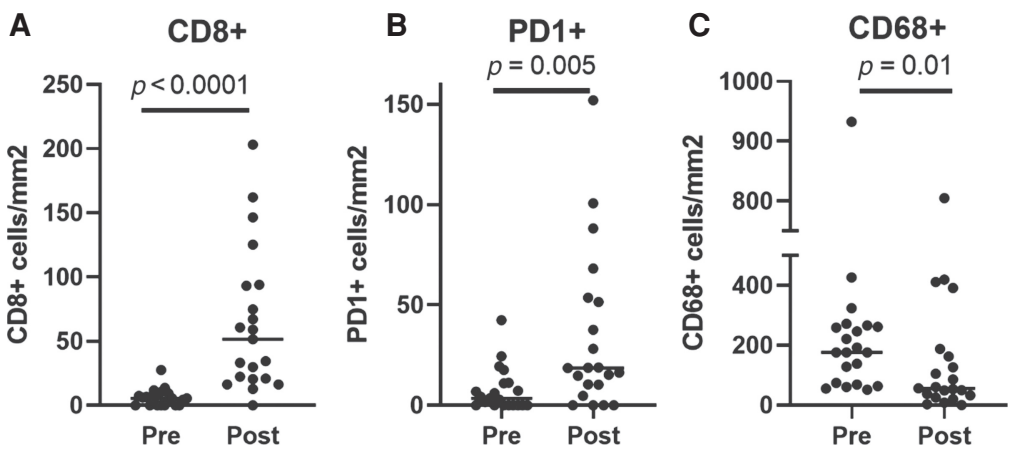

Figure 3. Quantification of cells positive for CD8 (A), PD1 (B), and CD68 (C) within the tumor epithelium, before and after treatment with pembrolizumab.

objective response in lymph nodes, persisting for $3 \mathrm{mo}$. Unfortunately, he subsequently developed worsening neurologic symptoms caused by further progression of his brain metastases despite ongoing control of his extra-CNS disease. At that time, he opted for comfort care measures only and died several weeks later. He survived a total of 12 mo following the initial diagnosis of brain metastases.

\section{DISCUSSION}

We present a patient with the rare diagnosis of prostate cancer with parenchymal brain metastases. We propose that our patient is especially unique, as his tumor also exhibited the rare feature of dMMR. dMMR refers to loss of at least one of four enzymes (MLH1, PMS2, $\mathrm{MSH} 2$, or MSH6) that participates in correction of DNA nucleotide pairing errors, resulting in accumulation of hundreds-to-thousands of single-nucleotide substitutions as well as small insertions/deletions within the cancer cell genome. This hypermutated genome may lead to formation of mutation-associated neoantigens (MANAs) that can be recognized by the immune system as foreign. Indeed, solid tumors with dMMR were found to have high response rates to the PD-1 inhibitor pembrolizumab regardless of cancer histology, leading to U.S. Food and Drug Administration (FDA) approval of use for this indication (Le et al. 2017). However, only a small percentage of prostate cancers have dMMR, with estimates ranging from 2\% to 4\% (Abida et al. 2019; Antonarakis et al. 2019).

The presence of these two rare diagnoses in our patient begs the question of whether they might be related. Interestingly, Sun et al. (2019) recently performed whole-exome sequencing on primary and metastatic brain tumors from 23 patients with colorectal cancer (CRC) and found that these brain metastases were enriched for mutational signatures of DNA damage repair (DDR) deficiency. This may suggest that extensive DNA damage may be advantageous for establishment of brain metastases. However, patients with dMMR primary CRC tumors do not appear to have higher rates of brain metastases, and one study suggested a trend toward a decreased risk of brain metastases in AMMR CRC (Prasanna et al. 2018). Therefore, it is unclear whether our patient's dMMR status contributed to his development of brain metastases. Of note, this patient's brain metastases also exhibited alterations in PTEN as well as NF1, which may support prior work suggesting a correlation between PTEN and NF1 inactivation and brain metastases in prostate cancer (Mota et al. 2019; Rodriguez et al. 2020).

Prostate cancers with dMMR have higher densities of TILs compared with MMR-proficient tumors (Guedes et al. 2017), yet our patient's tumor had a strikingly low density of 
TILs despite the dMMR status. This may be related to its growth within the brain parenchyma, as primary brain tumors are well known to exhibit intratumoral depletion of lymphocytes and enrichment of M2 macrophages (Thorsson et al. 2019). Low baseline TIL density (Tumeh et al. 2014), along with JAK1/2 mutation (Shin et al. 2017) and PTEN loss (Vidotto et al. 2020), are associated with resistance to anti-PD1 therapy (Tumeh et al. 2014); thus one may have predicted that these lesions would not respond. Indeed, our patient exhibited swift clinical CNS progression while on pembrolizumab. However, close inspection of the post-treatment tumor sample showed increased TIL density and depletion of macrophages. This suggests that pembrolizumab stimulated an antitumor immune response; whether this response was sufficient to result in tumor killing is unclear. Tumors exhibiting radiographic enlargement due to immune cell infiltration and not due to cancer cell proliferation (so-called "pseudoprogression") are well-described among CNS tumors (Brandsma et al. 2008) and among tumors treated with ICB (Jia et al. 2019). Pseudoprogression is definitively distinguished from true progression when the tumor is subsequently found to decrease in size despite no change in therapy. It is possible that pseudoprogression played a role in our patient's clinical course. Accurate noninvasive tests are needed to distinguish pseudoprogression from true progression; tests in development for this purpose include level of circulating tumor DNA (ctDNA) (Guibert et al. 2017; Lee et al. 2018), positron emission tomography (PET) using novel tracers such as fluoroethyl-tyrosine (FET) (Kebir et al. 2016), and MR assessment of hemodynamic alterations (Tsien et al. 2010). Of note, among patients with dMMR prostate cancer, high tumor frameshift mutation proportion (FSP) was associated with prolonged response to ICB in a prior study and is thought to be due to increased production of neoantigens (Sena et al. 2020). Despite a very low TIL density here, our patient's baseline tumor sample had a relatively high FSP of $22 \%$, which may have facilitated a response to pembrolizumab.

Among many cancer types, brain metastases exhibit variable responses to systemic therapy, perhaps owing to difficulty of agents penetrating the blood-brain barrier (Venur et al. 2018). A small study of 10 patients with high-grade glioma treated with pembrolizumab showed that pembrolizumab entered the cerebrospinal fluid (albeit at concentrations 0.009 times that of serum) and T cells isolated from cerebrospinal fluid (CSF) of these patients exhibited blockade of PD-1(Wang et al. 2020). Exciting work by Castro and Lowenstein suggests that tumor-specific immune responses in the CNS may be limited because of lack of dendritic cell antigen presentation, and adenoviral expression of Fms-like tyrosine kinase 3 ligand (FLT3-L) in CNS tumors to differentiate and recruit dendritic cells can lead to enhanced immune response within the CNS (Lowenstein and Castro 2018). This type of approach may be particularly effective to boost CNS responses in patients exhibiting systemic responses to ICB, as these patients have proven that their tumors are immunogenic within the extra-CNS compartment.

In spite of our patient's extra-CNS progression on multiple systemic therapies, it was our inability to control his brain metastases that ultimately led to his demise. In fact, at the time of his death, he continued to exhibit extra-CNS disease control using docetaxel despite worsening neurologic symptoms due to increasing ICP. Among patients with prostate cancer, median overall survival after diagnosis of brain metastases is typically 2-6 mo, but can be improved if treated with surgical resection (Hatzoglou et al. 2014; Mota et al. 2019). In this case, our patient survived 12 mo following his diagnosis of brain metastases. Of note, his progressive brain metastases impeded entry onto a clinical trial of immunotherapy for patients with $\mathrm{dMMR}$ cancers who have progressed on pembrolizumab (namely, the combination of a PD-1 inhibitor plus a LAG-3 inhibitor). Thus, this case illustrates the need for more clinical trials for patients with CNS metastases, including enrollment of patients with active or progressing brain metastases.

In summary, we report the case of a patient with mCRPC with parenchymal brain metastases and mismatch repair deficiency. This case provokes numerous questions regarding the 
COLD SPRING HARBOR Molecular Case Studies
dMMR prostate cancer with brain metastases interaction of tumor genetics, immune microenvironment, patterns of metastatic spread, and response to immunotherapy within and outside the CNS.

\section{METHODS}

\section{DNA Sequencing}

Targeted next-generation DNA sequencing of tumor samples was performed by Foundation Medicine using the FoundationOne CDx platform. A sequencing coverage table (Supplemental Table S2) is included in the Supplemental Data.

\section{Immunohistochemistry}

Immunohistochemistry for CD8 (Cell Marque 760-4250), PD-1 (Cell Marque 315M-96), CD163 (Novacastra NCL-CD163), MLH-1 (Ventana 790-5091), PMS2 (Ventana 790-5094), MSH2 (Ventana 790-5093), and MSH6 (Ventana 790-5092) were performed according to previous validated protocols in the Johns Hopkins CLIA-certified laboratory using the Ventana autostaining platform (Roche). Immunohistochemistry for FoxP3 (Abcam 20034, dilution 1:100) was performed with the OptiView DAB IHC Detection Kit (Roche) on a Ventana Discovery autostaining platform (Roche). Immunohistochemistry for NF-kB p65 Rabbit mAb (Cell Signaling 8242T, dilution 1:400) was performed with the OptiView DAB IHC Detection Kit (Roche) on a Ventana Discovery autostaining platform (Roche). A paraffin-embedded LNCaP cell line tissue microarray was used to validate the p65 immunostain. The immunohistochemistry stains were evaluated by two trained pathologists (D.C.S. and T.L.L.).

\section{Multiplex Immunofluorescence}

Automated mIF was performed as previously described (Giraldo et al. 2018; Davis et al. 2020). Briefly, slides were heated and dewaxed to remove any paraffin. Antigen retrieval was performed using ER2 followed by washing steps. Nonspecific staining was blocked using Blocking/Ab Diluent (Akoya Biosciences) followed by the first primary antibody (see position 1 in Supplemental Table S3). The corresponding polymer was applied followed by the tyramide signal amplification dye (Opal Automation Multiplex IHC Kit; Akoya Biosciences). Slides were heated to strip the primary antibody and polymer, washed, and blocked again. The process was repeated for positions 2-6. After the last step of antibody striping, the slides were stained for DAPI and coverslipped using ProLong Diamond Antifade Mountant (Life Technologies).

Slides were scanned using the Vectra Polaris Quantitative Pathology Imaging System (Akoya Biosciences). A $10 \times(1 \mu \mathrm{m} / \mathrm{px}$ ) whole-slide scan was acquired and used as a guide to select 20 high power field (HPF) for 20x image acquisition. These 20x HPF images were processed in Inform software (Akoya Biosciences) and exported to images with QPTIFF format.

\section{Multiplex Immunofluorescence Image Analysis}

The QPTIFF images were loaded into HALO (Indica Labs), and the tumor epithelium was manually annotated across 20 regions. The HighPlex FL V3.2.1 module of HALO was applied to identify cells with positive CD8, PD-1, and CD68 signals, and results were reported as positive cell densities (cells $/ \mathrm{mm}^{2}$ ) for each region. 
Competing Interest Statement

E.S.A. is a paid consultant/ advisor to Janssen, Astellas, Sanofi, Dendreon, Pfizer, Amgen, Lilly, Bayer, AstraZeneca, BristolMyers Squibb, Clovis, and Merck; he has received research funding to his institution from Janssen, Johnson \& Johnson, Sanofi, Dendreon, Genentech, Novartis, Tokai, Bristol Myers-Squibb, AstraZeneca, Clovis, and Merck; and he is the coinventor of an AR-V7 biomarker technology that has been licensed to QIAGEN. T.L.L. has received research funding from Roche, DeepBio and Myriad Genetics. The remaining authors report no conflicts of interest.

Referees

Alexander Wyatt

Anonymous

Received March 8, 2021; accepted in revised form April 19, 2021.

\section{ADDITIONAL INFORMATION}

\section{Data Deposition and Access}

Interpretation of the NFKBIA p.L187P variant was submitted to ClinVar (https://www.ncbi .nlm.nih.gov/clinvar/) under accession number VCV001170963.1. Consent was not obtained to make the patient's raw sequencing data publicly available.

\section{Ethics Statement}

This study was approved by the Johns Hopkins Institutional Review Board, and written informed consent for publication of this work was obtained from the spouse of the deceased patient.

\section{Acknowledgments}

We thank the laboratory of Sushant Kachhap for providing p65 KO LNCaP cells for antibody validation.

\section{Author Contributions}

L.A.S., T.L.L., and E.S.A. designed the study. D.C.S., E.L.E., and Q.Z. performed the experiments. L.A.S., D.C.S., and H.T. analyzed the data. T.L.L. and E.S.A. supervised the work. L.A.S. and E.S.A. wrote the manuscript. All authors reviewed and provided input for the manuscript.

\section{Funding}

This work was partially supported by the Patrick Walsh Prostate Cancer Research Fund (T.L.L. and E.S.A.), the National Institutes of Health Cancer Center Support Grant P30 CA006973, Department of Defense grants W81XWH-16-PCRP-CCRSA and W81XWH2010079, and the Bloomberg Kimmel Institute for Cancer Immunotherapy.

\section{REFERENCES}

Abida W, Cheng ML, Armenia J, Middha S, Autio KA, Vargas HA, Rathkopf D, Morris MJ, Danila DC, Slovin SF, et al. 2019. Analysis of the prevalence of microsatellite instability in prostate cancer and response to immune checkpoint blockade. JAMA Oncol 5: 471-478. doi:10.1001/jamaoncol.2018.5801

Antonarakis ES, Shaukat F, Isaacsson Velho P, Kaur H, Shenderov E, Pardoll DM, Lotan TL. 2019. Clinical features and therapeutic outcomes in men with advanced prostate cancer and DNA mismatch repair gene mutations. Eur Urol 75: 378-382. doi:10.1016/j.eururo.2018.10.009

Brandsma D, Stalpers L, Taal W, Sminia P, van den Bent MJ. 2008. Clinical features, mechanisms, and management of pseudoprogression in malignant gliomas. Lancet Oncol 9: 453-461. doi:10.1016/S1470-2045(08) 70125-6

Catane R, Kaufman J, West C, Merrin C, Tsukada Y, Murphy GP. 1976. Brain metastasis from prostatic carcinoma. Cancer 38: 2583-2587. doi:10.1002/1097-0142(197612)38:6<2583::AID-CNCR2820380652> 3.0.CO;2-D

Davis RJ, Lina I, Green B, Engle EL, Motz K, Ding D, Taube JM, Gelbard A, Hillel AT. 2020. Quantitative assessment of the immune microenvironment in patients with iatrogenic laryngotracheal stenosis. Otolaryngol Head Neck Surg 164: 1257-1264. doi:10.1177/0194599820978271

Gandaglia G, Abdollah F, Schiffmann J, Trudeau V, Shariat SF, Kim SP, Perrotte P, Montorsi F, Briganti A, Trinh Q-D, et al. 2014. Distribution of metastatic sites in patients with prostate cancer: a population-based analysis. Prostate 74: 210-216. doi:10.1002/pros.22742

Giraldo NA, Nguyen P, Engle EL, Kaunitz GJ, Cottrell TR, Berry S, Green B, Soni A, Cuda JD, Stein JE, et al. 2018. Multidimensional, quantitative assessment of PD-1/PD-L1 expression in patients with Merkel cell 
carcinoma and association with response to pembrolizumab. J Immunother Cancer 6: 99. doi:10.1186/ s40425-018-0404-0

Guedes LB, Antonarakis ES, Schweizer MT, Mirkheshti N, Almutairi F, Park JC, Glavaris S, Hicks J, Eisenberger MA, De Marzo AM, et al. 2017. MSH2 loss in primary prostate cancer. Clin Cancer Res 23: 6863-6874. doi:10.1158/1078-0432.CCR-17-0955

Guibert N, Mazieres J, Delaunay M, Casanova A, Farella M, Keller L, Favre G, Pradines A. 2017. Monitoring of KRAS-mutated ctDNA to discriminate pseudo-progression from true progression during anti-PD-1 treatment of lung adenocarcinoma. Oncotarget 8: 38056-38060. doi:10.18632/oncotarget.16935

Gupta A, Baidas S, Cumberlin RK. 1994. Brain stem metastasis as the only site of spread in prostate carcinoma. A case report. Cancer 74: 2516-2519. doi:10.1002/1097-0142(19941101)74:9<2516::AID-CNCR2820740 $920>3.0 . \mathrm{CO} ; 2-\mathrm{C}$

Hatzoglou V, Patel GV, Morris MJ, Curtis K, Zhang Z, Shi W, Huse J, Rosenblum M, Holodny Al, Young RJ. 2014. Brain metastases from prostate cancer: an 11-year analysis in the MRI era with emphasis on imaging characteristics, incidence, and prognosis. J Neuroimaging 24: 161-166. doi:10.1111/j.1552-6569.2012 .00767.x

Jia W, Gao Q, Han A, Zhu H, Yu J. 2019. The potential mechanism, recognition and clinical significance of tumor pseudoprogression after immunotherapy. Cancer Biol Med 16: 655-670.

Kebir S, Fimmers R, Galldiks N, Schäfer N, Mack F, Schaub C, Stuplich M, Niessen M, Tzaridis T, Simon M, et al. 2016. Late pseudoprogression in glioblastoma: diagnostic value of dynamic O-(2-[18 F]fluoroethyl)-L-tyrosine PET. Clin Cancer Res 22: 2190-2196. doi:10.1158/1078-0432.CCR-15-1334

Le DT, Durham JN, Smith KN, Wang H, Bartlett BR, Aulakh LK, Lu S, Kemberling H, Wilt C, Luber BS, et al. 2017. Mismatch repair deficiency predicts response of solid tumors to PD-1 blockade. Science 357: 409-413. doi:10.1126/science.aan6733

Lee JH, Long GV, Menzies AM, Lo S, Guminski A, Whitbourne K, Peranec M, Scolyer R, Kefford RF, Rizos H, et al. 2018. Association between circulating tumor DNA and pseudoprogression in patients with metastatic melanoma treated with anti-programmed cell death 1 antibodies. JAMA Oncol 4: 717-721. doi:10.1001/ jamaoncol.2017.5332

Lewis I. 1967. Cerebellar metastasis from prostatic carcinoma. A case report. Neurology 17: 698-702. doi:10 1212/WNL.17.7.698

Lowenstein PR, Castro MG. 2018. Evolutionary basis of a new gene- and immune-therapeutic approach for the treatment of malignant brain tumors: from mice to clinical trials for glioma patients. Clin Immunol 189: 4351. doi:10.1016/j.clim.2017.07.006

Mota JMSC, Teo MY, Knezevic A, Bambury RM, Hatzoglou V, Autio KA, Abida W, Gopalan A, Fine S, Danila DC, et al. 2019. Clinicopathologic and genomic characterization of parenchymal brain metastases (BM) in prostate cancer (PCa). J Clin Orthod 37: 227.

Nayak L, Lee EQ, Wen PY. 2012. Epidemiology of brain metastases. Curr Oncol Rep 14: 48-54. doi:10.1007/ s11912-011-0203-y

Prasanna T, Karapetis CS, Roder D, Tie J, Padbury R, Price T, Wong R, Shapiro J, Nott L, Lee M, et al. 2018. The survival outcome of patients with metastatic colorectal cancer based on the site of metastases and the impact of molecular markers and site of primary cancer on metastatic pattern. Acta Oncol 57: 1438-1444. doi:10.1080/0284186X.2018.1487581

Rodriguez A, Gallon J, Akhoundova D, Maletti S, Ferguson A, Cyrta J, Amstutz U, Garofoli A, Paradiso V, Tomlins SA, et al. 2020. The genomic landscape of prostate cancer brain metastases. bioRxiv doi:10 $.1101 / 2020.05 .12 .092296$

Saitoh H, Hida M, Shimbo T, Nakamura K, Yamagata J, Satoh T. 1984. Metastatic patterns of prostatic cancer. Correlation between sites and number of organs involved. Cancer 54: 3078-3084. doi:10.1002/1097-0142 (19841215)54:12<3078::AID-CNCR2820541245>3.0.CO;2-U

Sena LA, Fountain J, Isaacsson Velho P, Lim SJ, Wang H, Nizialek E, Rathi N, Nussenzveig R, Maughan BL, Velez MG, et al. 2020. Tumor frameshift mutation proportion predicts response to immunotherapy in mismatch repair-deficient prostate cancer. Oncologist 26: e270-e278. doi:10.1002/onco .13601

Shin DS, Zaretsky JM, Escuin-Ordinas H, Garcia-Diaz A, Hu-Lieskovan S, Kalbasi A, Grasso CS, Hugo W, Sandoval S, Torrejon DY, et al. 2017. Primary resistance to PD-1 blockade mediated by JAK1/2 mutations. Cancer Discov 7: 188-201. doi:10.1158/2159-8290.CD-16-1223

Smith VC, Kasdon DL, Hardy RC. 1980. Metastatic brain tumor from the prostate: two unusual cases. Surg Neurol 14: 189-191.

Sun J, Wang C, Zhang Y, Xu L, Fang W, Zhu Y, Zheng Y, Chen X, Xie X, Hu X, et al. 2019. Genomic signatures reveal DNA damage response deficiency in colorectal cancer brain metastases. Nat Commun 10: 3190 doi:10.1038/s41467-019-10987-3

Sutton MA, Watkins HL, Green LK, Kadmon D. 1996. Intracranial metastases as the first manifestation of prostate cancer. Urology 48: 789-793. doi:10.1016/s0090-4295(96)00238-5 
Taniguchi K, Karin M. 2018. NF-kB, inflammation, immunity and cancer: coming of age. Nat Rev Immuno/ 18: 309-324. doi:10.1038/nri.2017.142

Thorsson V, Gibbs DL, Brown SD, Wolf D, Bortone DS, Ou Yang T-H, Porta-Pardo E, Gao GF, Plaisier CL, Eddy JA, et al. 2019. The immune landscape of cancer. Immunity 51: 411-412. doi:10.1016/j.immuni.2019.08 .004

Tremont-Lukats IW, Bobustuc G, Lagos GK, Lolas K, Kyritsis AP, Puduvalli VK. 2003. Brain metastasis from prostate carcinoma: the MD Anderson Cancer Center experience. Cancer 98: 363-368. doi:10.1002/cncr .11522

Tsien C, Galbán CJ, Chenevert TL, Johnson TD, Hamstra DA, Sundgren PC, Junck L, Meyer CR, Rehemtulla A, Lawrence T, et al. 2010. Parametric response map as an imaging biomarker to distinguish progression from pseudoprogression in high-grade glioma. J Clin Oncol 28: 2293-2299. doi:10.1200/JCO.2009.25.3971

Tumeh PC, Harview CL, Yearley JH, Shintaku IP, Taylor EJM, Robert L, Chmielowski B, Spasic M, Henry G, Ciobanu V, et al. 2014. PD-1 blockade induces responses by inhibiting adaptive immune resistance. Nature 515: 568-571. doi:10.1038/nature13954

Venur VA, Karivedu V, Ahluwalia MS. 2018. Systemic therapy for brain metastases. Handb Clin Neurol 149: 137-153. doi:10.1016/B978-0-12-811161-1.00011-6

Vidotto T, Melo CM, Castelli E, Koti M, dos Reis RB, Squire JA. 2020. Emerging role of PTEN loss in evasion of the immune response to tumours. Br J Cancer 122: 1732-1743. doi:10.1038/s41416-020-0834-6

Wang D, Portnow J, Tran V, Chiu V, Brito A, Alizadeh D, Starr R, Kilpatrick J, McNamara P, Forman SJ, et al. 2020. Systemic anti-PD-1 immunotherapy results in PD-1 blockade on T cells in the cerebrospinal fluid. JAMA Oncol 16: 1947-1951. doi:10.1158/2326-6074.TUMIMM19-A52 


\section{COLD SPRING HARBOR Molecular Case Studies}

\section{Mismatch repair-deficient prostate cancer with parenchymal brain metastases treated with immune checkpoint blockade}

Laura A. Sena, Daniela C. Salles, Elizabeth L. Engle, et al.

Cold Spring Harb Mol Case Stud 2021, 7: a006094 originally published online June 17, 2021 Access the most recent version at doi: $10.1101 / \mathrm{mcs} . a 006094$
Supplementary http://molecularcasestudies.cshlp.org/content/suppl/2021/06/21/mcs.a006094.D Material C1

References This article cites 35 articles, 9 of which can be accessed free at: http://molecularcasestudies.cshlp.org/content/7/4/a006094.full.html\#ref-list-1

License This article is distributed under the terms of the Creative Commons Attribution-NonCommercial License, which permits reuse and redistribution, except for commercial purposes, provided that the original author and source are credited.

Email Alerting Receive free email alerts when new articles cite this article - sign up in the box at the Service top right corner of the article or click here. 